\title{
An Autocrine Role for Urokinase in Phorbol Ester-mediated Differentiation of Myeloid Cell Lines
}

\author{
A. Roomi Nusrat and Harold A. Chapman, Jr. \\ Department of Medicine, Brigham and Women's Hospital and Harvard Medical School, Boston, Massachusetts 02115
}

\begin{abstract}
The human myeloid cell line HL60 secretes urokinase-type plasminogen activator (uPA) and expresses its receptor. When stimulated with phorbol myristate acetate (PMA), both secretion of $\mathrm{uPA}$ and the expression of its receptor are up-regulated, and these cells differentiate to an adherent phenotype. This adhesive response is markedly reduced in the presence of uPA antibodies. The PMA response is restored by the addition of native uPA, an amino-terminal fragment of uPA (residues 1-143) devoid of proteolytic activity, or a synthetic peptide (residues 12-32) from the uPA growth factor domain known to mediate receptor binding. In contrast, the addition of catalytically active low molecular weight uPA, which is missing the growth factor domain, or a peptide from the catalytic domain (residues 247-266) is ineffective. The influence of uPA antibodies on a second marker of macrophage differentiation, cysteine proteinase activity, was also examined. Cysteine proteinase activity of HL60 cells is increased in PMA-treated cells after $24 \mathrm{~h}$ but it fails to increase in the presence of anti-uPA. This increase in cathepsin B-like activity is also restored by exogenous uPA. These experiments indicate that an autocrine interaction of the growth factor domain of $\mathrm{UPA}$ with its receptor mediates an essential step in PMA-mediated myeloid cell differentiation. (J. Clin. Invest. 1991. 87:1091-1097) Key words: cathepsin B • cell adhesion - HL60 cells • phorbol myristate acetate $\bullet$ urokinase receptor
\end{abstract}

\section{Introduction}

Many mammalian cells synthesize and release urokinase-type plasminogen activator (uPA) (1). ${ }^{1}$ Expression of this enzyme has been implicated in a wide variety of biological processes including cellular migration, connective tissue matrix turnover, trophoblastic implantation, and tumor transformation (2-5). Many if not all of the cells which secrete uPA, including

This work was presented in part at the Annual Meeting of the American Federation for Clinical Research, Washington, DC, May 1990.

Address reprint requests to Dr. Nusrat, Respiratory Division, Brigham and Women's Hospital, 75 Francis Street, Boston, MA 02115.

Received for publication 6 August 1990 and in revised form 22 October 1990.

1. Abbreviations used in this paper: $\mathrm{ATF}$, amino-terminal fragment (of urokinase); CD, catalytic domain; DFP, diisopropyl-fluorophosphate; GFD, growth factor domain; LMW, low molecular weight; uPA, urokinase-type plasminogen activator.

J. Clin. Invest.

(C) The American Society for Clinical Investigation, Inc. 0021-9738/91/03/1091/07 \$2.00

Volume 87, March 1991, 1091-1097 myeloid cell lines, monocytes, and macrophages, also express a high-affinity uPA receptor $(1,6-10)$. The amino-terminal region of the uPA molecule, termed the growth factor domain (residues 1-32), mediates binding of UPA to this receptor (11). Receptor-bound uPA on mononuclear phagocytes has a relatively long half-life (hours) and may be protected from inhibition by soluble plasminogen activator inhibitors, facilitating cellular migration and cell-mediated connective tissue turnover (12-15). Thus, one established role for cellular expression of UPA and its receptor is to focus plasminogen activator activity to the cell surface.

When stimulated with PMA, the anchorage-independent myeloid cell lines, THP-1, U937 and HL60, differentiate to an adherent phenotype that have many characteristics of macrophages (16-19). Among the known changes which follow PMA stimulation are increased secretion of UPA as well as increased expression of uPA receptors $(8,9,20-22)$. We now show that binding of the growth factor domain of uPA to its receptor plays an essential role in PMA-mediated myeloid cell adhesion and maturation. These data extend the functions ascribed to the uPA receptor to one that includes a role in signal transduction. The manuscript details work done with the HL60 cell line. However, the observations are similar for the PMA-responsive human leukemic THP-1 and U937 cells, indicating the generality of this phenomenon.

\section{Methods}

Reagents. RPMI 1640 was from Gibco Laboratories, Grand Island, NY; bovine fetal serum from Hyclone, Logan, UT; and tissue cultureware from Falcon Labware, Lincoln Park, NJ. Cell lines HL60, U937, and THP-1 cells were obtained from American Type Culture Collection, Rockville, MD. $\left[{ }^{3} \mathrm{H}\right]$ thymidine $(2 \mathrm{Ci} / \mathrm{mmol})$ was from New England Nuclear, Boston, MA. Two-chain high molecular weight urokinase was a gift of the American Red Cross, and $\geq 99 \%$ pure recombinant two-chain high molecular weight urokinase $(103,900 \mathrm{IU} / \mathrm{mg})$ from Chinese hamster ovary cells was a gift of Dr. Robert Broeze, Collaborative Research, Bedford, MA. 33-kD low molecular mass uPA (no detectable 54-kD uPA by zymography [23]), murine monoclonal anti-uPA (No. 377) and (No. 394), and protein-A affinity-purified rabbit anti-uPA (No. 389) were obtained from American Diagnostica, Greenwich, CT. Polyclonal rabbit anti-uPA (No. 6200) was purchased from Alpha Therapeutics, Los Angeles, CA. The amino-terminal fragment of uPA, residues 1-143, was a gift of Dr. Jack Henkin, Abbott Laboratories, Abbott Park, IL (24). Alkaline-phosphatase labeled goat anti-rabbit IgG (051506) was from Kirkegaard Perry, Gaithersburg, $\mathrm{MD}$; fluoresceinated $\mathrm{Fab}_{2}$ goat anti-mouse IgG from Zymed, San Francisco, CA; and supernatants of murine monoclonal hybridoma clone TS $1 / 18$ to the invariant chain of a family leucocyte cell adhesion molecules (25) were a gift of Dr. L. Kobzik, Harvard School of Public Health. Synthetic peptides comprising uPA residues 12-32 and 247266 were synthesized on a peptide synthesizer (model 9600, Biosearch/ Milligen, San Rafael, CA) and HPLC-purified. Boc-valine-leucine-lysine-aminomethylcoumarin and benzoyloxycarbonyl-phenylanalyl-arginine-4-methyl-7-aminomethylcoumarin (Z-Phe-Arg-NMec) were 
from Enzyme Systems Products, Livermore, CA. Silicone oil and dioctylphthalate was obtained from Aldrich Chemical Co., Milwaukee, WI. Protein A-purified neutralizing rabbit anti-bovine tissue factor, also effective against human tissue factor, was a gift of Dr. Ron Bach (26). Other chemical reagents were from Sigma Chemical Co., St. Louis, MO.

Cell culture. HL60 and U937 cells were cultured in RPM1 1640 supplemented with penicillin $(100 \mathrm{U} / \mathrm{ml})$, streptomycin $(100 \mu \mathrm{g} / \mathrm{ml})$, and $10 \%$ bovine fetal serum. For THP-1 cell culture medium, $48 \mu \mathrm{M}$ 2-mercaptoethanol was added to the mixture described above. Human alveolar macrophages were cultured in Dulbecco's modified Eagle's medium supplemented with $20 \mathrm{mM}$ Hepes, penicillin $(100 \mathrm{U} / \mathrm{ml})$, streptomycin $(100 \mu \mathrm{g} / \mathrm{ml})$, and $10 \%$ bovine fetal serum. All incubations were at $37^{\circ} \mathrm{C}, 5 \% \mathrm{CO} 2 / 95 \%$ air and cells were plated at $1 \times 10^{6} / \mathrm{ml}$. The cell lines were differentiated along the macrophage pathway with 16 nM PMA (16).

Bronchoalveolar lavage. After informed consent, normal volunteers with a history of smoking underwent bronchoalveolar lavage using a fiberoptic bronchoscope in a wedged position as previously described (27).

Assay for adherent cells. Adherent cells were assayed by three techniques: visualization by phase-contrast microscopy, incorporation of $\left[{ }^{3} \mathrm{H}\right]$ thymidine in the adherent cell population and by measurement of total adherent cell protein. Similar quantitative results were obtained when either adherent labeled cells or adherent cell protein was measured. Visual inspection consistently correlated with data obtained either by protein or $\left[{ }^{3} \mathrm{H}\right]$ thymidine incorporation assays. For thymidine incorporation, cells at $1 \times 10^{6} / \mathrm{ml}$ were labeled with $1 \mu \mathrm{Ci} / \mathrm{ml}\left[{ }^{3} \mathrm{H}\right]$ thymidine and pulsed with $16 \mathrm{nM}$ PMA, and $100 \mu \mathrm{l}$ of cells were dispensed in triplicates or quadruplicates in 96-well microtiter plates. After 16-24 $h$ of incubation, the plates was immersed in a beaker of normal saline, and nonadherent cells were flicked out. After three plate rinses the adherent cells were lysed in $50 \mu \mathrm{l}$ of lysis buffer (phosphate-buffered saline $\mathrm{pH} 7.4 / 10 \%$ glycerol $/ 0.2 \%$ sodium dodecyl sulfate $/ 0.2 \%$ Triton $\mathrm{X}-100$ ) and counted in a liquid scintillation counter. This assay scored cells in a similar physiological state, that is, cells tightly attached to the microtiter plates. Similarly, after the nonadherent cells were removed by the saline washes described above, adherent cell protein was assayed by hydrolyzing the cells in $5 \mathrm{~N} \mathrm{NaOH}$ for $4 \mathrm{~h}$ while the cells were on a microtiter plate shaker. The lysate was neutralized with equal volume 5 N HCL and protein was measured using the Bradford assay (No. 5000006, Bio-Rad Laboratories, Richmond, CA).

Assay for the effect of UPA on unstimulated HL60 cells. Cells at 1 $\times 10^{6} / \mathrm{ml}$ were pulsed with $0.1 \mu \mathrm{C} / \mathrm{ml}\left[{ }^{3} \mathrm{H}\right]$ thymidine in the presence of graded doses of uPA $(0-100 \mathrm{nM} / \mathrm{ml})$ and $100 \mu \mathrm{l}$ cells were dispensed in microtiter plates. $16-24 \mathrm{~h}$ later, the cells were harvested using an automatic cell harvester, and cell associated radioactivity on filters counted in a scintillation counter.

Diisopropylfluorophosphate (DFP) inactivation of $U P A$. uPA was inactivated with $5 \mathrm{mM}$ DFP at room temperature for one hour and exhaustively dialyzed. Residual catalytic activity was assayed fluorometrically using the plasmin dependent substrate Boc-val-leulys-aminomethylcoumarin, $0.2 \mathrm{mM}$, in the presence or absence of plasminogen, $5 \mu \mathrm{g} / \mathrm{ml}$. DFP treatment resulted in undetectable uPA activity.

Radiolabeled uPA equilibrium binding studies. uPA was radiolabeled by the method of Hunter and Greenwood (28), except that the amount chloramine-T was reduced to $30 \mu \mathrm{g}$ in a reaction volume of $115 \mu \mathrm{l}$. Unstimulated or cells stimulated overnight with $16 \mathrm{nM}$ PMA were used for equilibrium binding studies and Scatchard analysis performed. PMA-stimulated cells were scraped off the dishes with a rubber policeman $(8,9)$. Iodinated recombinant uPA was incubated in 3 $\times 10^{-12}$ to $9 \times 10^{-9} \mathrm{M}$ range with and without 100 -fold excess cold uPA for $2 \mathrm{~h}$ on ice. Bound radioactivity was separated by centrifugation through an oil cushion of 1:1 mixture of silicone oil and dioctylphthalate. Microfuge tips were cut and counted in a gamma counter. Initial studies confirmed previously reported observations of others that HL60 cells have specific saturable receptors for UPA in the subnano- molar range and that the receptor number increases five- to eightfold after overnight stimulation with PMA (9).

Assay of prourokinase antigen by ELISA. HL60 cells were maintained in serum free media containing $0.1 \%$ BSA supplemented with insulin, transferrin and selenium as described (21). Supernatants from control or overnight PMA stimulated cells were concentrated using filters with a $10-\mathrm{kD}$ cutoff from Amicon Corp., Danvers, MA. The sandwich ELISA consisted of a uPA monoclonal (No. 394) for antigen capture, polyclonal rabbit anti-uPA (No. 6200) as the second layer, and alkaline-phosphatase labeled goat anti-rabbit IgG for detection (29). This assay has no cross reactivity to tissue plasminogen activator. Fibrin zymography (23) verified that the supernatants from these cells contained a plasminogen activator that comigrated as a single clear 54-kD band identical to purified uPA. We found that the amount of prourokinase antigen in the supernatants of PMA stimulated cells increases by about 15 -fold as compared to control unstimulated cells, confirming work done by other investigators with the HL60 and U937 cell lines $(21,22)$.

Flow cytometry. Control unstimulated, or PMA-stimulated cells were cultured overnight with anti-uPA (No. 6200), $30 \mu \mathrm{l} / \mathrm{ml}$. PMA stimulated and anti-uPA treated nonadherent cells, $90 \%$ of total, were aspirated and treated with $\mathrm{pH} 3$ buffer to remove any cell associated uPA (10). They were then exposed sequentially to uPA ( $2 \mathrm{nM})$, monoclonal anti-uPA (No. 377) $(20 \mu \mathrm{g} / \mathrm{ml})$, and fluoresceinated $\mathrm{Fab}_{2}$ goat anti-mouse. Hybridoma supernatants of clone TS $1 / 18$ were used to assess CD18 expression (25). Nonspecific fluorescence was defined as that measured on cells exposed to a mixture of murine IgG1, IgG2a, and $\mathrm{IgG} 2 \mathrm{~b}$ (each $10 \mu \mathrm{g} / \mathrm{ml}$ ) followed by fluoresceinated $\mathrm{Fab}_{2}$. Analysis was performed using an Ortho 2151 cytofluorograph.

Cysteine proteinase assay. Z-Phe-Arg-NMec was used as a substrate for cathepsin B- and L-like cellular cysteine proteinases employing an assay based on that described by Barrett (30-32). Adherent and nonadherent cells were combined and centrifuged to separate them from supernatant fluid before lysis in a buffer composed of $20 \mathrm{mM}$ sodium acetate, $1 \%$ Triton X-100, $3 \mathrm{mM}$ EDTA at $\mathrm{pH} 5.5$, and subjected to a freeze-thaw cycle three times. The fluorometric assay was performed by incubating $10-$ or $20-\mu \mathrm{l}$ aliquots of lysates at $37^{\circ} \mathrm{C}$ in a total of one $\mathrm{ml}$ incubation buffer containing $20 \mathrm{mM}$ acetate, $10 \mu \mathrm{M}$ Z-Phe-Arg-NMec, $3 \mathrm{mM}$ cysteine at pH 5.5 for $30 \mathrm{~min}$. Incubation in the presence of the cysteine proteinase inhibitor L-3-carboxy-trans-2,3-epoxypropylleucylamido[4-guanidino]butane (E-64) was used to establish specificity of the assay (31). Each lysate was incubated in the presence or absence $1 \mu \mathrm{M}$ E-64 for the incubation period. Fluorescence was measured using an excitation wavelength of $383 \mathrm{nM}$ and emission wavelength of $460 \mathrm{nM}$. Cysteine proteinase activity was defined as E-64 inhibitable fluorescence and expressed as percent activity of unstimulated cells. Expression of fluorescence as a function of total protein in the lysates did not alter the results.

Statistical analysis. Student's $t$ test was performed for comparison of paired mean experimental values (33).

\section{Results}

Urokinase antibodies affect the adhesion of PMA stimulated HL60 cells. Overnight stimulation with PMA results in $\sim 50 \%$ of the cells differentiating to an adherent phenotype (16). This response to PMA was tested in the presence of rabbit antibodies to uPA (anti-uPA). Adherence to plastic was assayed as one index of differentiation. Cells were pulsed with $\left[{ }^{3} \mathrm{H}\right]$ thymidine at the time of PMA stimulation and the number of adherent cells at 16-24 h determined by quantitation of residual activity in culture wells washed to remove nonadherent cells. Half a microgram of affinity purified anti-uPA per microtiter well resulted in a $50 \%$ reduction, and $20 \mu \mathrm{g}$ in $>85-90 \%$ reduction in adherent cells as compared to control wells (Fig. 1). A similar effect of anti-uPA was observed on the PMA response of HL60 
cells maintained in serum-free medium as well as with U937 and THP-1 cells (not shown). Nonimmune rabbit IgG and neutralizing anti-tissue factor antibody did not attenuate cellular adherence (26). The addition of control nonimmune IgG consistently resulted in more cells adhering than in PMA only wells (Fig. 1). This observation was not explored further.

The anti-uPA effect illustrated in Fig. 1 could be due to toxicity, neutralization of uPA enzymatic activity, or interference with binding of uPA to its receptor. Equilibrium receptor binding studies demonstrated that $20 \mu \mathrm{g}$ of affinity-purified anti-uPA per $100 \mu \mathrm{l}$ of cells reduced specific binding of $1 \mathrm{nM}$ iodinated uPA to 24-h PMA stimulated HL60 cells by $\geq 85 \%$. The viability of PMA-stimulated, antibody-treated, nonadherent cells was slightly reduced. These nonadherent cells were $15 \pm 5 \%(n=6)$ trypan blue positive whereas control cells in culture were $\leq 5 \%$ positive. However, the addition of exogenous uPA (100 nM) to these antibody-treated cells resulted in an increase in the number of adherent cells to values comparable to PMA only treated cells. This reversibility suggested that the reduction in adhesion was not due to toxicity and but rather involved a specific interaction of uPA with uPA antibodies.

Determination of the $U P A$ domain(s) necessary for adhesion. As shown in Fig. 2, uPA is a multidomain protein within the serine proteinase family. At the amino terminus is a growth factor domain followed by a connecting peptide, a kringle structure, and carboxy-terminal catalytic domain (1). We tested various fragments of uPA for their ability to reverse the effect of anti-uPA shown in Fig. 1. Previous work has established that a catalytically inactive amino-terminal fragment of uPA (ATF), residues 1-135, as well as synthetic peptides from the growth factor domain (residues 1-32) compete effectively with $\mathrm{UPA}$ for binding to the UPA receptor $(11,20)$. A peptide comprising residues $12-32$ (21 amino acids) from the growth factor domain (GFD-peptide) known to be effective in this competition was synthesized. As a control for the GFD-peptide, a peptide comprising residues 247-266 (20 amino acids) from the catalytic domain (CD-peptide) was also made. The serine proteinase inhibitor, DFP, irreversibly inactivates uPA (DFP-uPA), and DFP-uPA interacts with uPA receptor as avidly as the active enzyme (34). Catalytically active 33-kD low

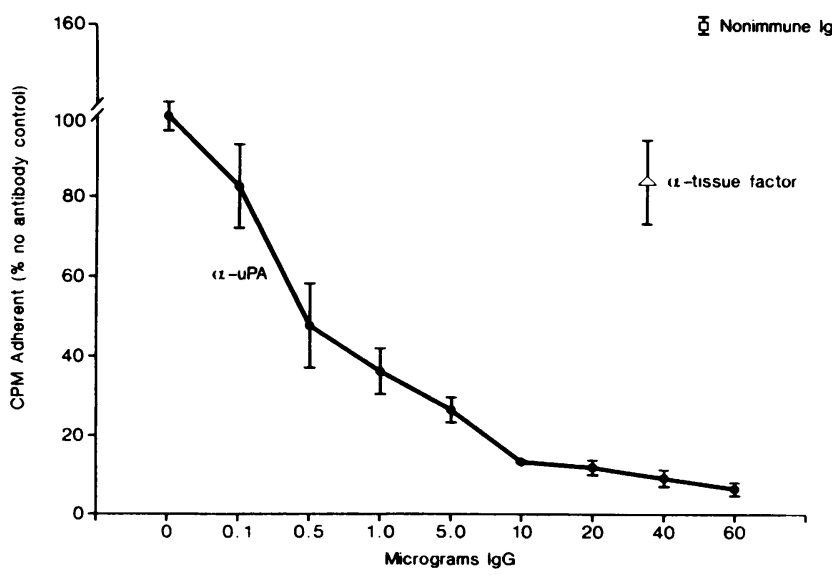

Figure 1. Protein A-purified rabbit anti-uPA blocks adhesion of PMA-stimulated HL60 cells. Indicated amounts of antibody was added at the time of PMA pulse. Values are displayed as percent of control (no added antibody). Comparable results were obtained with both affinity-purified or nonaffinity-purified anti-uPA.

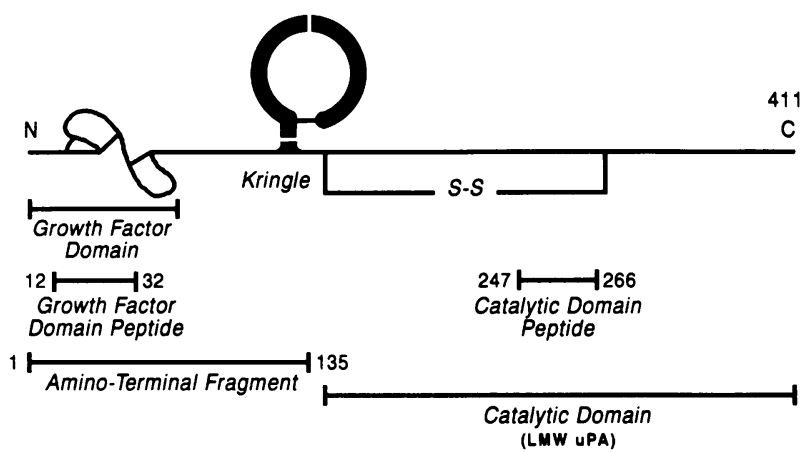

Figure 2. Schematic representation of the urokinase molecule and its fragments used in the experiments. The ATF used here consisted of residues $1-143$ (eight residues longer than the ATF originally described by Stoppelli et al. [20]) and does not have the catalytic domain. LMW-uPA is the 33-kD form of the molecule comprising the catalytic domain and has no receptor binding activity. GFDpeptide is residues 12-32 from the growth factor domain, and $C D$ peptide is residues $247-266$ from the catalytic domain. Diagram modified from Francis and Marder [54].

molecular weight form of uPA (LMW-uPA), a proteolytically cleaved product of the native molecule devoid of the aminoterminal fragment, does not bind to the uPA receptor (34). All of these fragments and forms of uPA were tested for their ability to overcome the effect of anti-uPA on PMA-stimulated cells.

Fig. 3 presents data from these experiments which have been reproduced at least three times. When PMA stimulated cells are cultured in the presence of anti-uPA sufficient to decrease the number of adherent cells by at least $85 \%$, the addition of UPA, DFP-uPA, ATF, and the GFD-peptide is associated with a dose-dependent increase in the number of adherent cells. In addition, segments of uPA which include the

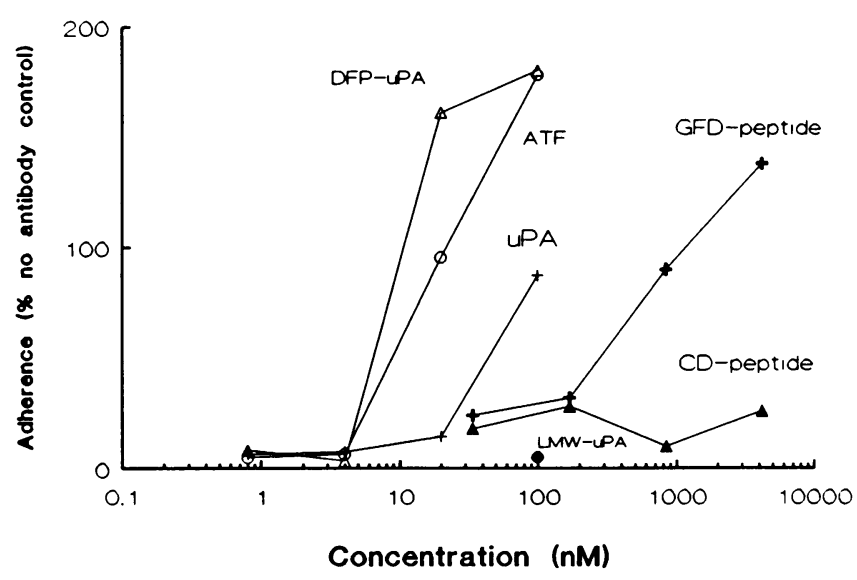

Figure 3. Inhibition of adhesion by anti-uPA antibodies is reversible. Experiments were performed as described in Fig. 1 with adherence measured as counts per minute $\left[{ }^{3} \mathrm{H}\right]$ thymidine. The various forms of UPA were added at the time of PMA pulse to test for their ability to overcome the effect of anti-uPA. The uPA fragments tested are described in Fig. 2 and the text. Values are displayed as percent of control (no added antibody). In separate experiments, uPA itself was also shown to be effective in increasing the number of adherent cells to $>100 \%$ of control values. $100 \mathrm{nM} \mathrm{LMW-uPA}$ did not reverse the effect of anti-uPA. 
growth factor domain are capable of increasing the adherent cell number to values greater than that seen with PMA alone $(100 \%)$. Fragments of the uPA molecule which have only the catalytic domain (LMW-uPA), or just a peptide fragment from this domain (CD-peptide) are ineffective in reversing the antiuPA effect. Experiments with U937 and THP-1 cells also demonstrated that the anti-uPA mediated block in adhesion could be reversed with either uPA or GFD-peptide (not shown).

Photomicrographs of the effect of anti-uPA on the PMA response of HL60 cells and the reversal of this phenomenon by ATF are shown in Fig. 4. PMA stimulated cells are adherent and spread (Fig. $4 A$ ). In the presence of anti-uPA very few cells adhere (Fig. $4 B$ ), but with the addition of ATF, $25 \mathrm{nM}$, the cells are again adherent and spread (Fig. $4 C$ ). The presence of more cells in Fig. $4 C$ is related to the amount of ATF used as illustrated in Fig. 3. Higher concentrations of ATF result in almost two times more cells adhering than in PMA only control wells. These findings indicate that uPA fragments which include the growth factor domain, regardless of the catalytic domain, will promote the PMA-induced adherent phenotype.

Effect of the GFD peptide on PMA response. Data in Fig. 5 show that for PMA stimulated cells in the presence of antiuPA, portions of the uPA molecule possessing the GFD increase the number of adherent cells above control values. Therefore, the effect of the GFD-peptide itself on the PMA response was tested in the absence of uPA antibodies. The addition of the GFD-peptide at the time of PMA stimulation resulted in a dose-dependent increase in the number of adhering cells (Fig. 5). When visualized using phase-contrast microscopy, the PMA and GFD-peptide stimulated cells appeared more well spread and dense compared with PMA only treated counterparts. This observation was additional support for a role of the growth factor domain in augmenting PMA-triggered maturation. In contrast, the control CD-peptide from the catalytic domain did not alter the number of adhering cells.

Effect of exogenous urokinase on $H L 60$ proliferation. It has been reported that for the CCL 20.2 human epidermal cell line that uPA can serve as an autocrine mitogen and stimulates thymidine incorporation (42). However, this activity requires the presence of both the GFD and an active catalytic domain. We tested to see if exogenous uPA has any effect on HL60 cells. When uPA (0-100 $\mathrm{nM})$ is added to cells in the absence of PMA, we observed no induction of adherence and the cells remain viable. In addition, there was no increase in the proliferation of cells as indicated by $\left[{ }^{3} \mathrm{H}\right]$ thymidine incorporation studies. After overnight incubation, control cells incorporated $5,610 \pm 171 \mathrm{cpm}$. The thymidine uptake in the presence of uPA was as follows: $0.8 \mathrm{nM}(5,830 \pm 86 \mathrm{cpm}), 4 \mathrm{nM}(5,593 \pm 431$ cpm), $20 \mathrm{nM}(5,799 \pm 194 \mathrm{cpm})$, and $100 \mathrm{nM}(5,578 \pm 244$ $\mathrm{cpm})$. This data is representative of one of three experiments, each done in triplicate. Thus, exogenous uPA does not have a proliferative effect on these cells.

Lack of effect of UPA antibodies on adhesion of differentiated HL60 cells and human alveolar macrophages. Human alveolar macrophages, obtained by bronchoalveolar lavage, were tested to assess the effect of anti-uPA on mature tissuetype macrophages. These cells are known to synthesize and bind uPA $(7,27)$. An overnight adherence assay similar to that

- described in Fig. 1, but without PMA was used. There was no difference in adherence between anti-uPA-treated or untreated macrophages (Table I). Moreover, uPA antibodies added to HL60 cells $72 \mathrm{~h}$ after PMA stimulation did not result in appre-

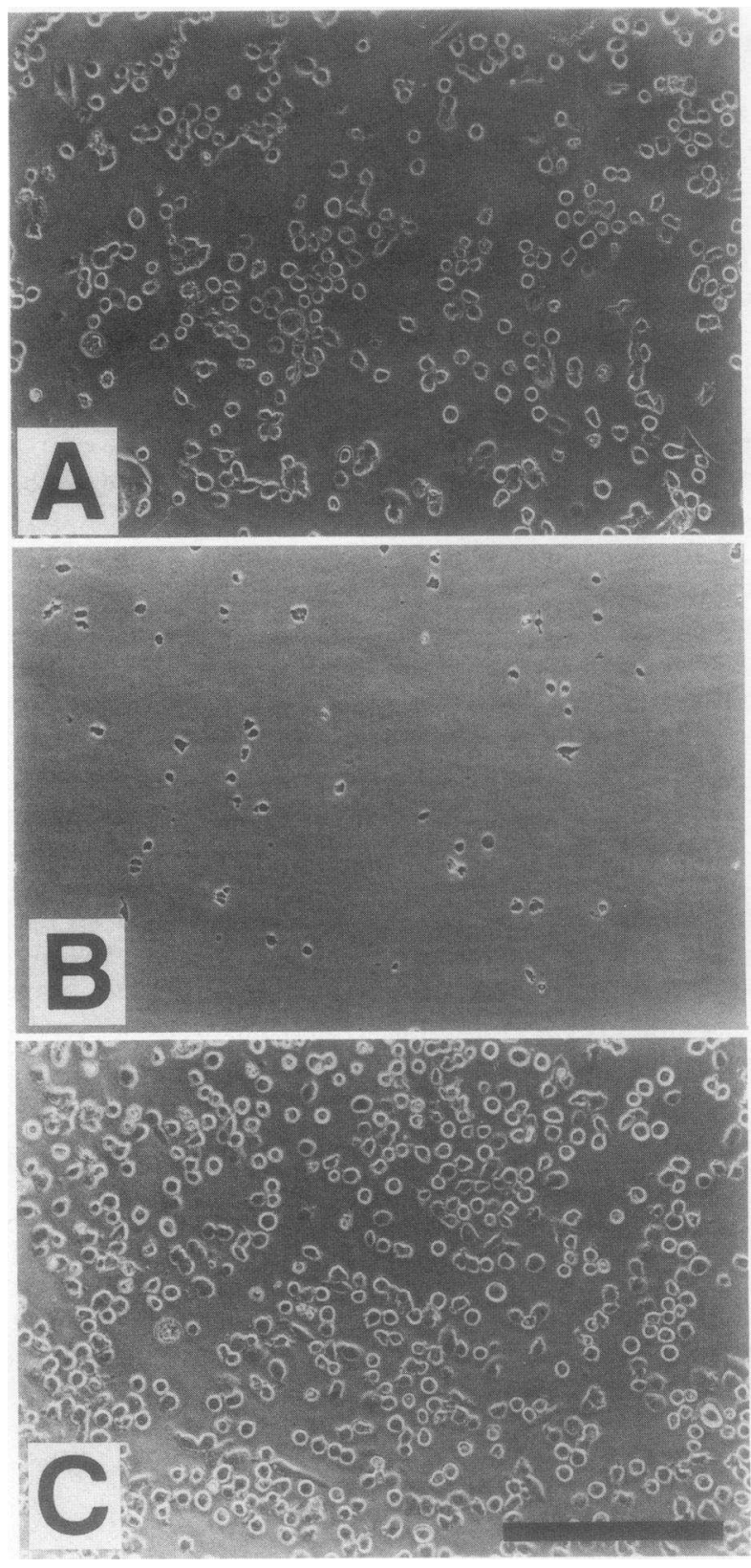

Figure 4. Inhibition of PMA induced adhesion of HL60 cells by anti-uPA antibodies is reversed by the amino-terminal fragment of uPA. Cells were cultured as described in Methods and Figs. 1 and 3. $(A)$ Control PMA stimulated cells. $(B)$ Cells stimulated with PMA in the presence of rabbit anti-uPA to reduce adherence by $\geq 85 \%$. (C) Cells as in B with the addition of $25 \mathrm{nM}$ ATF. Bar, $200 \mu \mathrm{m}$.

ciable detachment of adherent cells (not shown). These observations suggested that anti-uPA may interfere with the process of myeloid cell differentiation and not directly with attachment.

Anti-uPA antibodies block PMA induced increase in cellular cysteine proteinase activity. Macrophages are characterized by high levels of acidic lysosomal proteinases, including members of the cysteine proteinase family such as cathepsin B and $\mathrm{L}(35,36)$. PMA-induced differentiation of HL60 cells is also associated with a significant increase in cathepsin B and L-like activity in cell lysates as measured by cleavage of the 


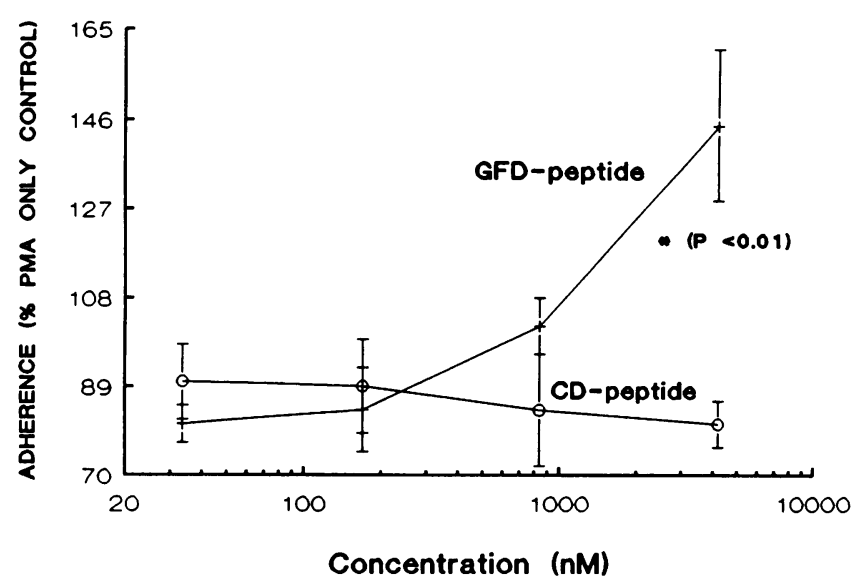

Figure 5. GFD-peptide augments the PMA adhesive response in a dose-dependent fashion. The addition of the growth factor domain peptide alone at the time of PMA stimulation significantly increases the number of adherent HL60 cells. Control CD-peptide from the carboxy terminus does not have this effect. Data from one of three comparable experiments. Adherence was measured as counts per minute $\left[{ }^{3} \mathrm{H}\right]$ thymidine.

synthetic substrate Z-phe-arg-NMec at pH 5.5 (30-32). Fig. 6 illustrates that the lysates of PMA-treated cells have an almost twofold increase in cathepsin B-like activity when compared with untreated HL60 cells $(P<0.05, n=4)$. The class specific cysteine proteinase inhibitor E-64 reduced the cleavage of this substrate by $\geq 80 \%$ indicating that the increase in activity is due principally to cysteine proteinases. PMA treatment in the presence of anti-uPA prevents cells from adhering and results in a significant reduction in cysteine proteinase activity $(P$ $=0.012, n=4)$. As indicated in Fig. 6 , the addition of uPA ( 100 $\mathrm{nM}$ ) at the time of addition of the antibody overcomes this effect, the cells adhere, and the induction of cysteine proteinase activity is restored.

PMA-stimulated and UPA antibody-treated cells express $U P A$ receptors. To determine the status of $\mathrm{uPA}$ receptors on nonadhering HL60 cells stimulated by PMA in the presence of anti-uPA, analyses by flow cytometry were performed. The expression of UPA receptors as indicated by cell surface uPA staining is increased $\sim 30$-fold on these nonadhering cells (Ta-

Table I. Anti-uPA Does Not Effect Adherence of Human Alveolar Macrophages

\begin{tabular}{cc}
\hline Treatment & Cells adherent \\
\hline$\mu$ l anti- $\mu P A$ & $\mu g$ adherent cell protein \\
None & $6.1 \pm 0.5$ \\
0.63 & $8.0 \pm 1.2$ \\
1.25 & $9.4 \pm 0.8$ \\
2.5 & $7.5 \pm 1.0$ \\
5.0 & $8.4 \pm 1.3$ \\
\hline
\end{tabular}

Human alveolar macrophages $\left(100-\mu l\right.$ aliquots of $\left.1 \times 10^{6} / \mathrm{ml}\right)$ were incubated in microtiter plates with anti-uPA in the indicated quantities at the time of initiation of cell culture. After overnight culture, the wells were washed and adherent cell protein measured. PMA-stimulated HL60 cells in the presence of $2.5 \mu \mathrm{l}$ of anti-uPA have a $>85 \%$ reduction in adherence.

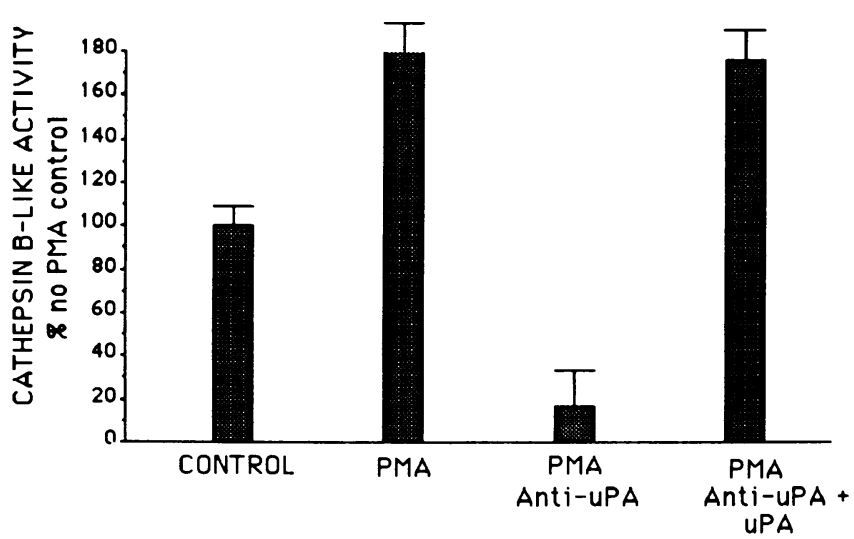

Figure 6. Anti-uPA $(25 \mu \mathrm{l} / \mathrm{ml})$ inhibits accumulation of cellular cysteine proteinase activity in response to PMA, and exogenous uPA overcomes this effect. Activity of total HL60 cell lysates, adherent and nonadherent, is shown. $100 \mathrm{nM}$ uPA was used to reverse the effect of anti-uPA. Data represent E64 inhibitable cysteine proteinase activity.

ble II). Adherence of mononuclear phagocytes is associated with cell surface expression of molecules from the integrin family $(37,38)$. The effect of uPA antibodies on adhesion could be due to interference with the expression of these molecules. Therefore staining for CD18, the invariant chain of a family of cell adhesion molecules, was also performed (25). The observed increase in CD18 after the PMA pulse was about twofold (Table II), similar to previously reported values using comparable assay conditions (39). Thus uPA antibodies, while blocking adhesion and induction of macrophage cysteine proteinase activity, do not eliminate PMA-induced increases in $\mathrm{uPA}$ receptor and CD18 antigen.

\section{Discussion}

Data presented here demonstrate for the first time that macrophage differentiation of myeloid cells by phorbol esters is mediated in part by an autocrine interaction of the growth factor domain of uPA with its receptor. Several lines of evidence sup-

Table II. HL60 Cells Exposed to PMA and Anti-uPA Antibodies Increase Expression of UPA Receptors

\begin{tabular}{llcc}
\hline & & \multicolumn{2}{c}{ Mean fluorescence } \\
\cline { 3 - 4 } Surface antigen & & \multicolumn{2}{c}{ arbitrary units } \\
\hline \multirow{3}{*}{ uPA receptor } & Exp A. & 10.2 & $321.4(31 \times)$ \\
& Exp B. & 11.6 & $404.4(35 \times)$ \\
CD 18 & Exp A. & 190.4 & $278.2(1.5 \times)$ \\
& Exp B. & 175.0 & $354.2(2 \times)$ \\
& & & \\
\hline
\end{tabular}

Control unstimulated HL60 cells, or PMA stimulated cells in the presence of UPA antibody were prepared for flow cytometry as described in Methods. The quantity of anti-uPA used ( $3 \mu \mathrm{l} / 100 \mu \mathrm{l}$ cells) resulted in $\geq 90 \%$ of PMA-stimulated cells not adhering. The mean nonspecific fluorescence in two separate experiments was $15.7 \pm 7.6$ arbitrary units with no difference between unstimulated and stimulated cells. The values in parentheses indicate magnitude change with respect to unstimulated controls. 
port this conclusion. PMA stimulation is known to increase both the secretion of UPA and the expression of UPA receptors on myeloid cell lines $(8,9,21,22)$. We have shown that antiuPA will inhibit the binding of uPA to its receptors. When HL60 cells are treated with anti-uPA at the time of PMA stimulation there is increased cell surface expression of uPA receptors and the CD18 antigen; however, there is an inhibition of other markers of differentiation such as adherence and cathepsin B-like activity. The addition of UPA, ATF, or a 21 residue peptide from the GFD reverses this inhibition of differentiation by uPA antibodies. In contrast, the catalytic domain of UPA or a control peptide from this domain fails to reverse this effect. Thus, the catalytic domain does not appear to play a major role in this process. These data indicate that uPA mediates two different functions in macrophage physiology: an autocrine function (GFD dominated) independent of enzymatic activity, and a catalytic function (serine proteinase domain dominated) involving plasminogen activation. The former being important in macrophage ontogeny and the latter important in cellular movement and extracellular matrix metabolism. Both functions are mediated, at least in part, by interactions between uPA and its receptor.

It is of interest that the growth factor domain augments the PMA-induced differentiation and adhesion of cells when added by itself (Fig. 5). This observation raises the possibility that in addition to an autocrine mechanism, uPA may influence myeloid cell differentiation in a paracrine fashion. Because fibroblasts, endothelial cells, neutrophils, and monocytes are able to secrete uPA (1), stromal and inflammatory cells may have a prominent role in modulating macrophage differentiation in vivo.

The secretion of plasminogen activators by human bone marrow cells has previously been linked to their differentiation. Early human granulocyte/macrophage progenitor cells secrete tissue-type plasminogen activator (tPA) whereas more mature granulocyte and macrophage progenitor cells secrete uPA $(40,41)$. Although the reason for this change in pattern in enzyme secretion is not known, our data suggest a mechanism by which uPA secretion and myeloid cell differentiation may be mechanistically linked.

Evidence that the uPA receptor may transduce signalling has been suggested in other experimental systems. For certain epidermal cells, uPA has been found to be a weak mitogen, and the data have indicated that both the growth factor domain and the catalytic domain are necessary (42). In view of these observations, we measured the proliferative response of HL60 cells after stimulation with exogenous uPA (0.8-100 nM range), and found that there was no change in ${ }^{3} \mathrm{H}$-thymidine uptake or induction of adherence. Thus for these cells, uPA itself does not induce differentiation and the second signal, PMA, which acts via protein kinase $\mathrm{C}$ is also required. Furthermore, it has been shown that uPA in the absence of its catalytic activity can mediate a chemotactic role for neutrophils and aortic endothelial cells indicating that the uPA receptor can alter cell activity (43, 44). Murine erythroleukemia (Friend) cells differentiated in vitro have a significant reduction in time for commitment to terminal differentiation when cultured in the presence of ATF (45), consistent with our observations with the effect of the GFD-peptide and ATF on PMA-stimulated myeloid cells.

These and our observations contrast with those where the catalytic domain of uPA bound to its receptor appears to play a role in matrix metabolism and detachment from culture sur- faces. For Rous sarcoma virus-transformed chicken embryo fibroblasts and mesangial epithelial cells, treatment with antiuPA directed against the catalytic uPA domain promotes adhesion and prevents the morphological effects induced by PMA or cyclic-AMP mediated pathways $(46,47)$. Moreover, in maturing Friend erythroleukemia cells, where evidence exists for a role of ATF in inducing differentiation, monoclonal antibodies directed against the catalytic domain promote adhesion on fibronectin coated surfaces presumably by interfering with metabolism of the matrix (48).

Induction of cathepsin B-like lysosomal proteinase activity is a reliable marker of macrophage differentiation $(32,35,36)$. Our data show that the addition of uPA antibodies to PMAstimulated HL60 cells not only blocked induction of this proteinase activity, but also resulted in lower fluorometric activity than that of unstimulated cells (Fig. 6). The reason for the latter is not clear. It is possible that uPA has a "trophic" effect for these cells along the lines reported for various colony stimulating factors (49). This would be consistent with the small decrease in viability in antibody-treated cells as compared with control unstimulated cells. It is also possible that the fluorometric activities in control and PMA-stimulated and UPA antibody-treated cells are due to different enzymes. The synthetic substrate employed could be hydrolyzed by more than one cysteine proteinase. Since our data show that not all attributes of PMA-induced differentiation are blocked by uPA antibodies (Table II), the lower activity in PMA-stimulated and antibody treated cells compared to unstimulated cells could reflect a difference in enzyme ratio during a state of stimulation when cells cannot adhere.

Accumulating evidence indicates that cell shape and cellular interactions with extracellular matrices modulate gene expression and differentiation (50-52). For example, adhesion of monocytes to plastic surfaces has been reported to regulate cfos and m-CSF mRNA (53). Adhesion appears to be both a marker for and an intrinsic part of myeloid cell differentiation. Our data indicate that uPA receptor binding modulates both cathepsin B-like enzyme expression as well as cell adhesiveness. It remains to be defined whether the observed block in cathepsin B-like activity (Fig. 6) results from attenuated adhesiveness or from a more proximate block in differentiation affecting both markers. A useful aspect of the experimental system presented here is that it offers a convenient model where the consequences of interaction of uPA with its receptor can be explored. Further structural and functional studies should delineate the importance of this pathway in understanding another set of mechanisms which regulate myeloid cell behavior.

\section{Acknowledgments}

The authors thank Drs. J. Drazen, L. Kobzik, R. J. Broeze, D. O'Hara, N. Stimler, and J. Swanson, for helpful discussions and advice. M. Zeidel kindly permitted use of his laboratory and reagents. L. Z. Sailor and A. Colby provided excellent technical support. Dr. Nusrat is recipient of NRSA HL8002. Dr. Chapman is a Career Investigator of the American Lung Association. This study was supported by HL-35505, NIH ES 0002, and a grant (2289) from the Council for Tobacco Research.

\section{References}

1. Blasi, F. 1988. Surface receptors for urokinase plasminogen activator. Fibrinolysis. 2:73-84. 
2. Liotta, L., R. H. Goldfarb, R. Brundage, G. P. Siegal, V. Terranova, and S. Garbisa. 1981. Effect of plasminogen activator (urokinase), plasmin, and thrombin on glycoprotein and collagenous components of basement membrane. Cancer Res. 41:4629-4636.

3. Saksela, O. 1985. Plasminogen activation and regulation of pericellular proteolysis. Biochim. Biophys. Acta. 832:35-65.

4. Valinsky, J. E., E. Reich, and N. M. Le Douarin. 1981. Plasminogen activator in the Bursa of Fabricius: correlations with morphogenetic remodeling and cell migrations. Cell. 25:471-476.

5. Ossowski, L. 1988. In vivo invasion of modified chorioallantoic membrane by tumor cells: the role of cell surface-bound urokinase. J. Cell Biol. 107:24372445.

6. Kirchheimer, J. C., Y.-H. Nong, and H. G. Remold. 1988. Interferongamma, tumor necrosis factor-alpha, and urokinase regulate the expression of urokinase receptors of human monocytes. J. Immunol. 141:4229-4234.

7. Chapman, H. A., P. Bertozzi, L. S. Zenzius, and R. Nusrat. 1990. Human alveolar macrophage urokinase receptor: role in localizing enzyme activity to the cell surface. Am. J. Physiol. In press.

8. Picone, R., E. L. Kajtaniak, L. S. Nielsen, N. Behrendt, M. R. Mastronicola, M. V. Cubellis, M. P. Stoppelli, S. Pedersen, K. Dano, and F. Blasi. 1989. Regulation of urokinase receptors in monocytelike U937 cells by phorbol ester phorbol myristate acetate. J. Cell Biol. 108:693-702.

9. Nielsen, L. S., G. M. Kellerman, N. Behrendt, R. Picone, K. Dano, and F. Blasi. 1988. A 55,000-60,000 $M_{\mathrm{r}}$ receptor protein for urokinase-type plasminogen activator. J. Biol. Chem. 263:2358-2363.

10. Stoppelli, M. P., C. Tacchetti, M. V. Cubellis, A. Corti, V. J. Hearing, G. Cassani, E. Appella, and F. Blasi. 1986. Autocrine saturation of prourokinase receptors on human A431 cells. Cell. 45:675-684.

11. Appella, E., E. A. Robinson, S. J. Ullrich, M. P. Stoppelli, A. Corti, G. Cassani, and F. Blasi. 1987. The receptor-binding sequence of urokinase. J. Biol. Chem. 262:4437-4440.

12. Chapman, H. A., Z. Vavrin, and J. B. Hibbs. 1982. Macrophage fibrinolytic activity. Identification of two pathways of plasmin formation by intact cells and of a plasminogen activator inhibitor. Cell. 28:653-662.

13. Kirchheimer, J. C., and H. G. Remold. 1989. Functional characteristics of receptor-bound urokinase on human monocytes: catalytic efficiency and susceptibility to inactivation by plasminogen activator inhibitors. Blood. 74:1396-1402

14. Cubellis, M. V., P. Andreasen, P. Ragno, M. Mayer, K. Dano, and F. Blasi. 1989. Accessibility of receptor-bound urokinase to type-1 plasminogen activator inhibitor. Proc. Natl. Acad. Sci. USA. 86:4828-4832.

15. Ellis, V., T.-C. Wun, N. Behrendt, E. Ronne, and K. Dano. 1990. Inhibition of receptor-bound urokinase by plasminogen-activator inhibitors. J. Biol. Chem. 265:9904-9908.

6. Rovera, G., D. Santoli, and C. Damsky. 1979. Human promyelocytic leukemia cells in culture differentiate into macrophage-like cells when treated with a phorbol diester. Proc. Natl. Acad. Sci. USA. 76:2779-2783.

17. Harris, P., and P. Ralph. 1985. Human leukemic models of myelomonocytic development: a review of the HL-60 and U937 cell lines. J. Leukocyte Biol. 37:407-422.

18. Collins, S. J. 1987. The HL60 promyelocytic leukemia cell line: proliferation, differentiation, and cellular oncogene expression. Blood. 70:1233-1244.

19. Tsuchiya, S., Y. Kobayashi, Y. Goto, H. Okumura, S. Nakae, T. Konno, and K. Tada. 1982. Induction of maturation of cultured human monocytic leukemia cells by a phorbol diester. Cancer Res. 42:1530-1536.

20. Stoppelli, M. P., A. Corti, A. Soffientini, G. Cassani, F. Blasi, and R. K. Assoian. 1985. Differentiation-enhanced binding of the amino-terminal fragment of the human urokinase plasminogen activator to a specific receptor on U937 monocytes. Proc. Natl. Acad. Sci. USA. 82:4939-4943.

21. Alving, B. M., C. Krishnamurti, Y.-P. Liu, D. L. Lucas, and D. G. Wright. 1988. Stimulated production of urokinase and plasminogen activator inhibitor-2 by human promyelocytic leukemia cell line HL60. Thromb. Res. 51:175-185.

22. Genton, C., E. K. O. Kruithoff, and W.-D. Schleuning. 1987. Phorbol ester induces the biosynthesis of glycosylated and nonglycosylated plasminogen activator inhibitor 2 in high excess over urokinase-type plasminogen activator in human U-937 lymphoma cells. J. Cell Biol. 104:705-712.

23. Granelli-Piperno, A., and E. Reich. 1978. A study of proteases and protease-inhibitor complexes in biological fluids. J. Exp. Med. 148:223-234.

24. Barnathan, E. S., A. Kuo, L. Rosenfeld, K. Kariko, M. Leskit, F. Robbiati, M. L. Nolli, J. Henkin, and D. B. Cines. Interaction of single-chain urokinasetype plasminogen activator with human endothelial cells. J. Biol. Chem. In press.

25. Sanchez-Madrid, F., J. Nagy, E. Robbins, P. Simon, and T. A. Springer 1983. A human leukocyte differentiation antigen family with distinct alpha-subunits and a common beta-subunit. J. Exp. Med. 158:1785-1803.

26. Bach, R., Y. Nemerson, and W. Konigsberg. 1981. Purification and characterization of bovine tissue factor. J. Biol. Chem. 256:8324-8331.

27. Chapman, H. A., O. L. Stone, and Z. Vavrin. 1984. Degradation of fibrin and elastin by intact human alveolar macrophages in vitro: characterization of a plasminogen activator and its role in matrix degradation. J. Clin. Invest. 73:806815.
28. Hunter, W. M., and F. C. Greenwood. 1962. Preparation of iodine labelled human growth hormone of high specific activity. Nature (Lond.). 194:495496.

29. Harlow, E., and D. Lane. 1988. Antibodies: a Laboratory Manual. Cold Spring Harbor Press, Cold Spring Harbor, NY. 553-612.

30. Barrett, A. J. 1980. Fluorimetric assays for cathepsin B and cathepsin H with methylcoumarylamide substrates. Biochem. J. 187:909-912.

31. Barrett, A. J., and H. Kirschke. 1981. Cathepsin B, cathepsin H, and cathepsin L. Methods Enzymol. 80:535-561.

32. Burnett, D., J. Crocker, and A. T. M. Vaughan. 1983. Synthesis of cathepsin B by cells derived from the HL60 promyelocytic leukemia cell line. J. Cell. Physiol. 115:249-254.

33. Colton, T. 1974. Statistics in Medicine. Little, Brown \& Company, Boston, MA. 128-143.

34. Vassalli, J-D., D. Baccino, and D. Belin. 1985. A cellular binding site for the $M_{\mathrm{r}} 55,000$ form of the human plasminogen activator, urokinase. J. Cell Biol. 100:86-92.

35. Chang, J. C., M. Lesser, O. H. Yoo, and M. Orlowski. 1986. Increased cathepsin B-like activity in alveolar macrophages and bronchoalveolar lavage fluid from smokers. Am. Rev. Respir. Dis. 134:538-541.

36. Reilly, J. R., R. W. Mason, P. Chen, L. J. Joseph, V. P. Sukhatme, R. Yee, and H. A. Chapman. 1989. Synthesis and processing of cathepsin L, an elastase, by human alveolar macrophages. Biochem. J. 257:493-498.

37. Anderson, D. C., L. J. Miller, F. C. Schmalsteig, R. Rothlein, and T. A. Springer. 1986. Contributions of the Mac-1 glycoprotein family to adherence-dependent granulocyte functions: Structure-function assessments employing subunit-specific monoclonal antibodies. J. Immunology. 137:15-27.

38. Miller, L. J., D. F. Bainton, N. Borregaard, and T. A. Springer. 1987. Stimulated mobilization of monocyte Mac-1 and p150,95 adhesion proteins from an intracellular vesicular compartment to the cell surface. J. Clin. Invest. 80:535-544.

39. Rosmarin, A. G., S. C. Weil, G. L. Rosner, J. D. Griffin, M. A. Arnaout, and D. G. Tenen. 1989. Differential expression of CD1/b/CD18 (Mol), and myeloperoxidase genes during myeloid differentiation. Blood. 73:131-136.

40. Wilson, E. L., G. E. Francis. 1987. Differentiation-linked secretion of urokinase and tissue plasminogen activators by normal human hemopoetic cells. J. Exp. Med. 165:1609-1623.

41. Wilson, E. L., P. Jacobs, and E. B. Dowdle. 1983. The secretion of plasminogen activators by human myeloid leukemic cells in vitro. Blood. 61:568574.

42. Kirchheimer, J. C., J. Wojta, G. Christ, and B. R. Binder. 1987. Proliferation of a human epidermal tumor cell line stimulated by urokinase. FASEB (Fed. Am. Soc. Exp. Biol.) J. 1:125-128.

43. Gudewicz, P. W., and N. Gilboa. 1987. Human urokinase-type plasminogen activator stimulates chemotaxis of human neutrophils. Biochem. Biophys. Res. Commun. 147:1176-1181.

44. Fibbi, G., M. Ziche, L. Morbidelli, L. Magnelli, and M. Del Rosso. 1988. Interaction of urokinase with specific receptors stimulates mobilization of bovine adrenal capillary endothelial cells. Exp. Cell. Res. 179:385-395.

45. Del Rosso, M., M. Pucci, G. Fibbi, and G. Dini. 1987. Interaction of urokinase and specific receptors abolishes the time of commitment to terminal differentiation of murine erythroleukaemia (Friend) cells. Br. J. Haematol. 66:289-294.

46. Sullivan, L. M., and J. P. Quigley. 1986. An anticatalytic monoclonal antibody to avian plasminogen activator: its effect on behavior of RSV-transformed chick fibroblasts. Cell. 45:905-915.

47. Glass, W. F. II., R. A. Radnik, J. A. Garoni, and J. I. Kreisberg. 1988. Urokinase-dependent adhesion loss and shape change after cyclic adenosine monophosphate elevation in cultured rat mesangial cells. J. Clin. Invest. 82:1992-2000

48. Amici, C., A. Benedetto, O. Saksela, E.-M. Salonen, and A. Vaheri. 1989. Plasminogen activator and its enhancement in differentiating mouse Friend erythroleukemia cells. Int. J. Cancer. 43:171-176.

49. Metcalf, D. 1985. The granulocyte-macrophage colony-stimulating factors. Science (Wash. DC.). 229:16-22.

50. Haskill, S., C. Johnson, D. Eierman, S. Becker, and K. Warren. 1988. Adherence induces selective mRNA expression of monocyte mediators and proto-oncogenes. J. Immunol. 140:1690-1694.

51. Kaplan, G., and G. Gaudernack. 1982. In vitro differentiation of human monocytes: differences in monocytic phenotype induced by cultivation on glass or collagen. J. Exp. Med. 156:1101-1114.

52. Fuhlbrigge, R. C., D. D. Chaplin, J.-M. Kiely, and E. R. Unanue. 1987 Regulation of interleukin 1 gene expression by adherence and lipopolysaccharide. J. Immunol. 138:3799-3802.

53. Eierman, D. F. C. E. Johnson, and J. S. Haskill. 1989. Human monocyte inflammatory mediator gene expression is selectively regulated by adherence substrates. J. Immunol. 142:1970-1976.

54. Francis, C. W., and V. J. Marder. 1987. Physiologic regulation and pathologic disorders of fibrinolysis. Hum. Pathol. 18:263-274. 